\title{
Architectural Engineering of FRP Bridges
}

\section{Joris SMITS}

architect, civil engineer, lecturer

Delft University of Technology

Delft, the Netherlands

J.E.P.smits@tudelft.nl

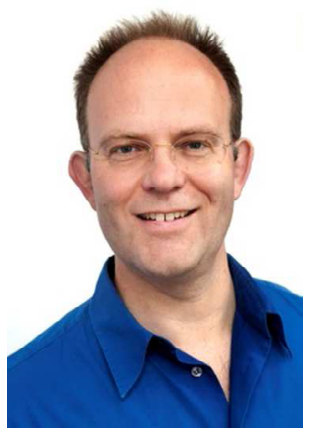

Joris graduated at the TU Delft where he combined Civil Engineering and Architecture. His understanding of structural design has profoundly defined him as an architect. He has designed a wide range of bridges and has won prizes all over the world. His designs are rational yet expressive. Since 2012 he combines his architect's practice with lecturing at TU Delft.

\section{Summary}

This paper deals with the use of Fibre Reinforced Polymers (FRP'S) in architectural and structural bridge design. The challenges and opportunities that come with this relatively new material are discussed. An inventory is made of recent engineers' solutions in FRP, followed by a discussion on architectural application of FRP's derived from the authors architectural practice.

Keywords: architecture; structural design; bridge design; FRP; Juliana Bridge; fly-over

Waarderpolder; Wildlife crossing Rijssen-Wierden; Dragonfly Bridge Harderwijk; Delft Design Composite Bridge.

\section{Introduction}

Albeit the fact that the building industry is very conservative compared to other industries such as the automotive or the aerospace industry, new materials and innovative techniques are finding their way into the bridge industry. One of these innovative materials is Fibre Reinforced Polymers (FRP). In the Netherlands alone we have seen a growing number of FRP bridges being realized over the past few years. Most of these bridges have been engineered as a straightforward loadbearing board with railings mounted on top. Yet FRP has a lot to offer in terms of the aesthetical appearance of a bridge.

Our best practices in FRP demonstrate our belief that innovation and progress is not something we should be shy about. Every new material has its own unique characteristics that call for a unique design approach. Freedom of form, texture and colour are only some of the many aspects that that enable us to express uniqueness in FRP bridge designs. We have designed smooth and shiny bridge edge elements that bestow a slender and modern appearance to a bridge. We have also developed slender and daring monocoque structures that span over 25 meters. But always it is the material itself that forms the chief inspiration for all our designs. 


\section{Engineers solutions:}

In order to better understand the potentials of FRP for the aesthetical design of bridges, we must first look at the way engineers have been using this relatively new material over the past two decades. Although some architect would like to think otherwise, it was engineers that started using FRP in bridge design over the past two decades, not architects. Driven by maintenance and durability issues engineers were looking for alternatives to steel and concrete. None of the early FRP designs expressed much concern for aesthetics or slenderness. However the advantages in terms of cost saving were evident. The average FRP bridge is about half the weight of a steel bridge with the same performance and is five times lighter than its concrete compeer. The gain on weight also saves on transportation costs, foundation costs, hoisting and assembly costs. In terms of durability there are great advantages too. FRP does not corrode and is inapt to de-icing salt or chemicals. Furthermore FRP has excellent fire resistant properties.

One has to give credits to those engineers that pioneered with FRP in bridge design. They explored a new frontier were no bridge engineer had gone before, although many aerospace-, maritime- and automotive engineer had preceded them in decades before, starting as early as 1940 when Henry Ford produced a composite car from hemp fibre and resin, under the motto: ' $10 \mathrm{x}$ stronger than steel!'.
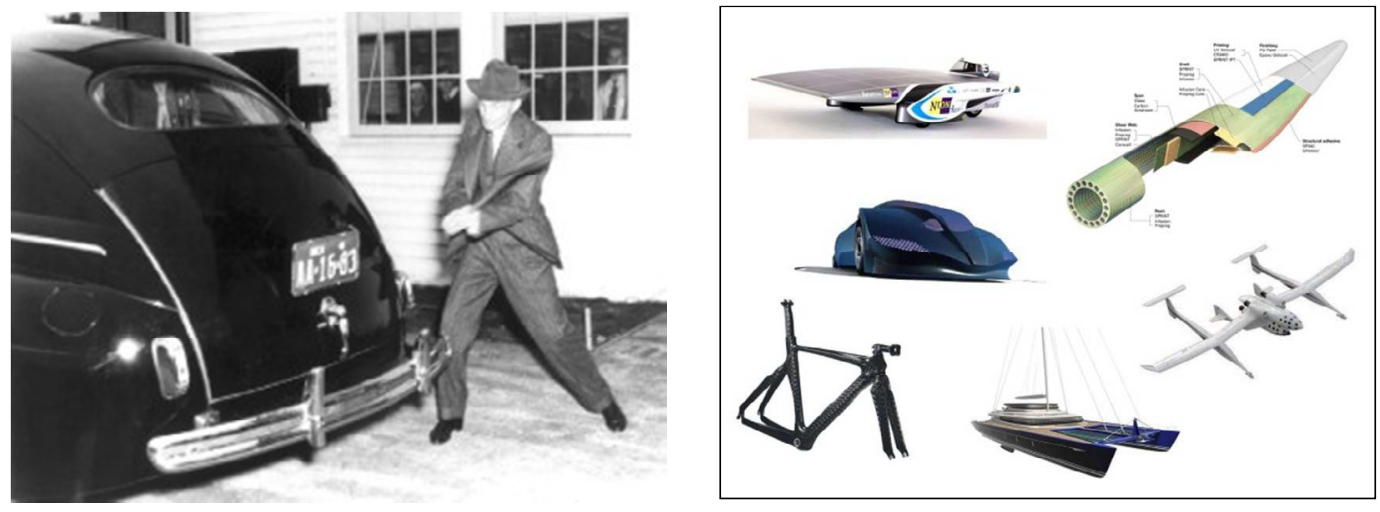

Figure 1: Henry Ford demonstrates his hemp car on impact. [Ford, 1940]

Figure 2: engineers from aerospace, maritime, automotive and sports industries have preceded bridge engineers

\subsection{Hand lamination, footbridge in Harlingen}

In December 1995 the Dutch ministry of Infrastructure (Rijkswaterstaat) was the first to initiate a $100 \%$ FRP footbridge in the Netherlands. In December 1997 this hand laminated bridge was put to use in the harbour of Harlingen. The bridge was half the weight of a traditional steel bridge, twice the price and its span-to-depth ratio (L/D) was twice as low due to the U-beam concept with massive loadbearing parapets.
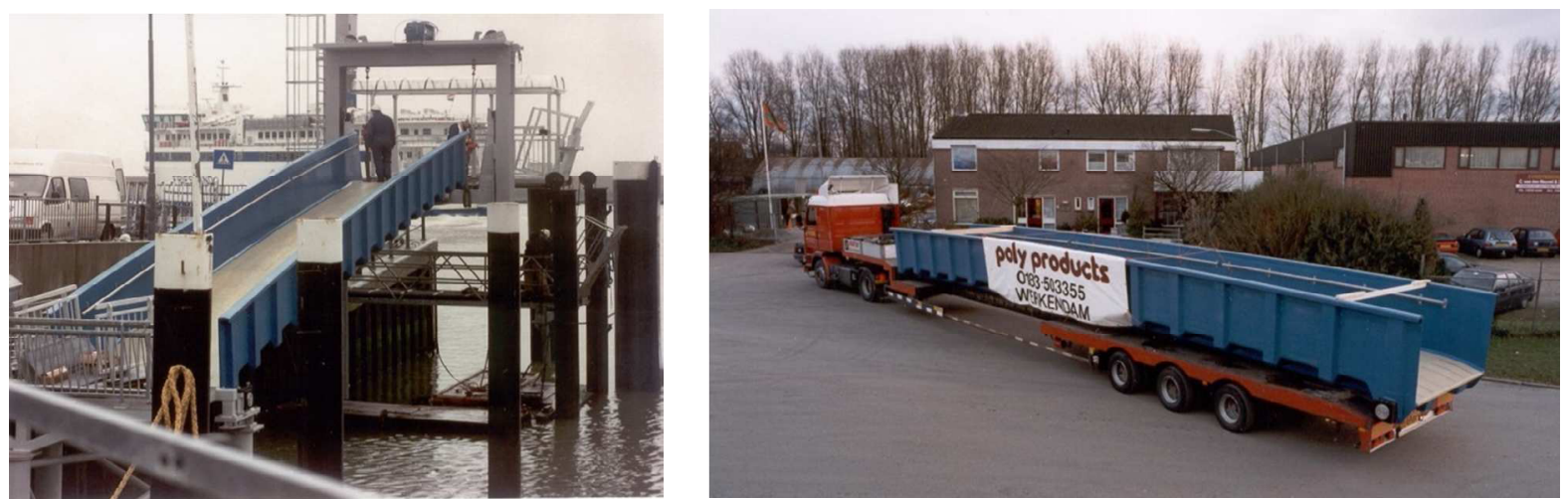

Figure 3: Footbridge in Harlingen, the Netherlands [Poly products, 1997] 


\subsection{Assembly from pultrusion profiles}

In other countries then the Netherlands, FRP pultrusion profiles were often used to construct a bridge. Pultrusion is a continuous automated process to produce large quantities of identical parts, which translates into relatively low priced elements of consistent quality. Complex cross-sectional shapes and high fiber fractions can be achieved with the pultrusion process. Reinforcement is pulled through a resin bath and subsequently through a heated die. The die tapers into the final profile shape along its length, and the continuous profile emerges fully cured to be cut to length. A wide range of solid and hollow structures with constant cross-section can be produced that can be applied as bridge beams, deck panels, grating systems, handrails etc. The fibres can however only be oriented in the longitudinal axis, resulting in dominating mechanical properties in the axial direction. To obtain some degree of bidirectional properties woven fabrics or mats can be fed to the die to be integrated in laminate, but transverse properties remain limited [Mazumdar, 2002].

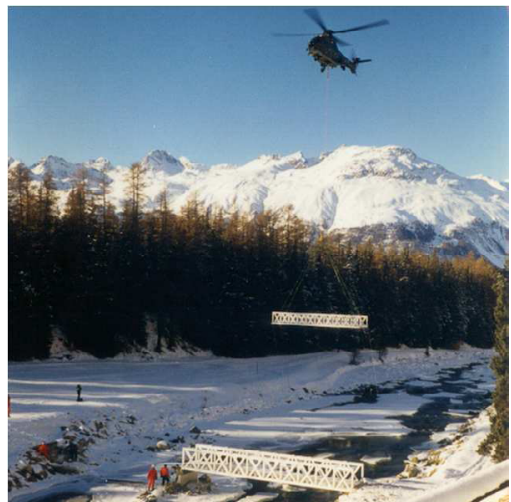

(a) Pontresina, Switzerland

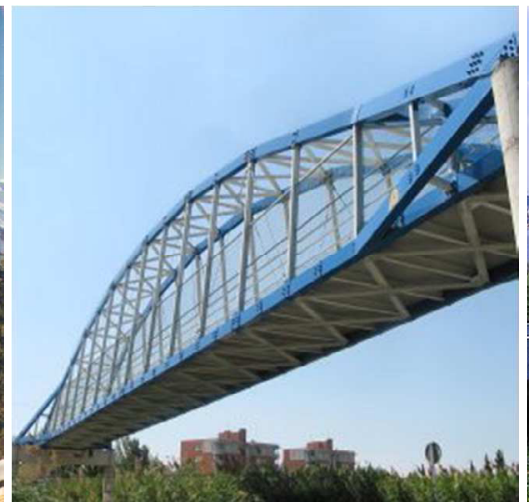

(b) Lleida, Spain

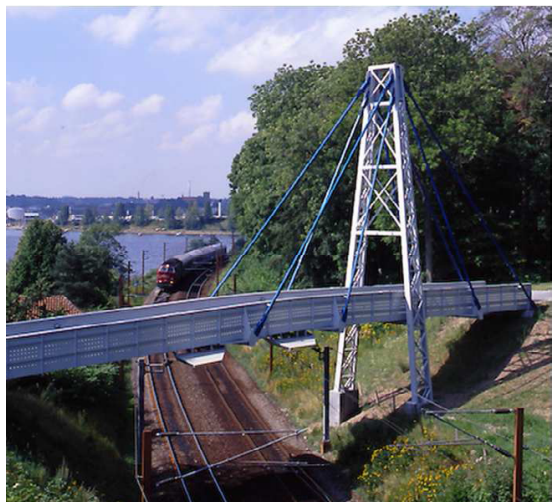

(c) Kolding, Denmark

Figure 4: Bridge structures from pultruded profiles - material substitution [Fiberline, 2013]

In terms of detailing a pultrusion FRP bridge looks a lot like a steel bridge. Straight profiles and pultrude sheets are assembled into trusses, arches, pylons or U-beams. The joints are the crux when using pultrusion profiles. Because the fibres are unidirectional in the length of the profile, they are apt to split near the joints and are often thick with bolts and plates.

\subsection{Bridge decks}

Bridge decks are generally the least durable part of bridges. Poor initial construction, the lack of proper maintenance and environmental conditions reduce the service life of bridge decks to an estimated average of ten to fifteen years. With the exclusion of painting, bridge deck repair and replacement can account for between 75 and 90 percent of the annual maintenance costs [Karbhari et al., 2001]. Next to using composites to replace deteriorated steel or concrete decks, they can also be applied to widen existing structures without significantly adding dead loads for piers and abutments.

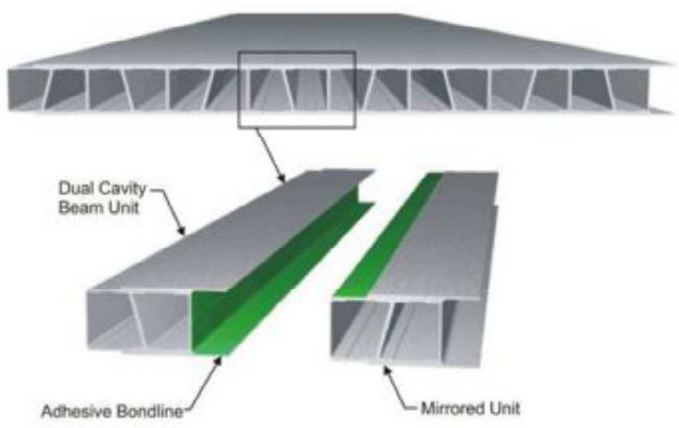

Figure 5: Pultruded bridge deck panels [Transportation Research Board, 2006] 


\subsection{Loadbearing uniform deck}

The Netherlands has seen quit a large growth in FRP footbridges and bicycles bridges over the past decade. One Dutch company called FiberCore is responsible for most of them. The bridges they produce are very efficient and straightforward, constructed as a hollow FRP plank with steel railings mounted on top of them. The production process is patented by FiberCore and comprises a series of parallel positioned, non-load bearing core elements, which are wrapped in continuous woven fabrics. The reinforcement continuously runs from the element's horizontal face planes through the webs and the facings of adjacent core elements. The elements are positioned on a deformable mould plate. Subsequently the structure is sealed and resin is drawn into the reinforcement by a vacuum technique. Dependent of the equipment used, the web and flange thickness can be up to tens of centimetres, having fibre fractions of up to 70 percent. The core material generally does not fulfil a structural role in the final product, but is merely used as formwork in the production process. The foam should be able to resist the vacuum pressure during the impregnation process, and should furthermore be lightweight and cheap [Peeters, 2011].

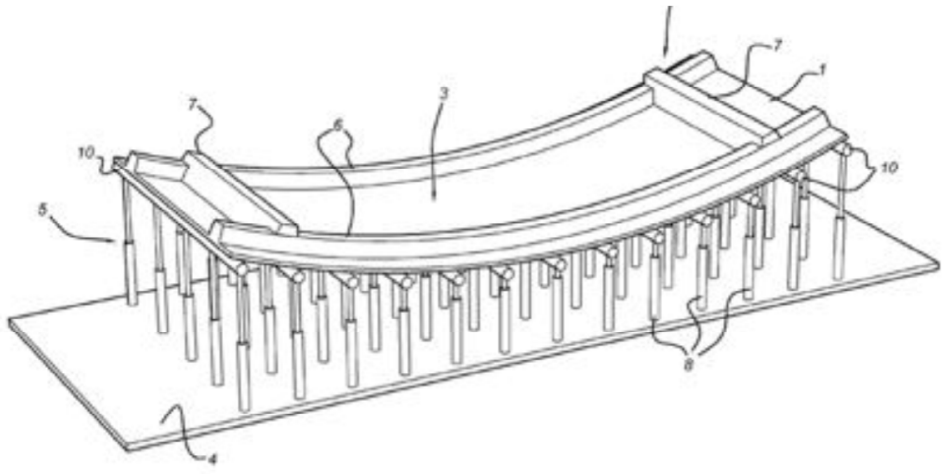

(a) Flexible mould system

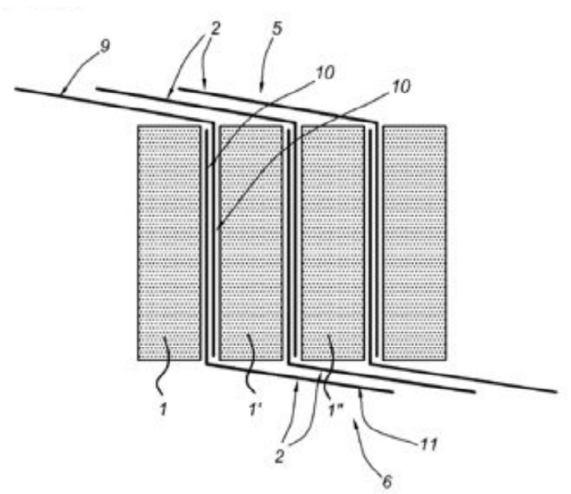

(b) Continuous face-web fibres

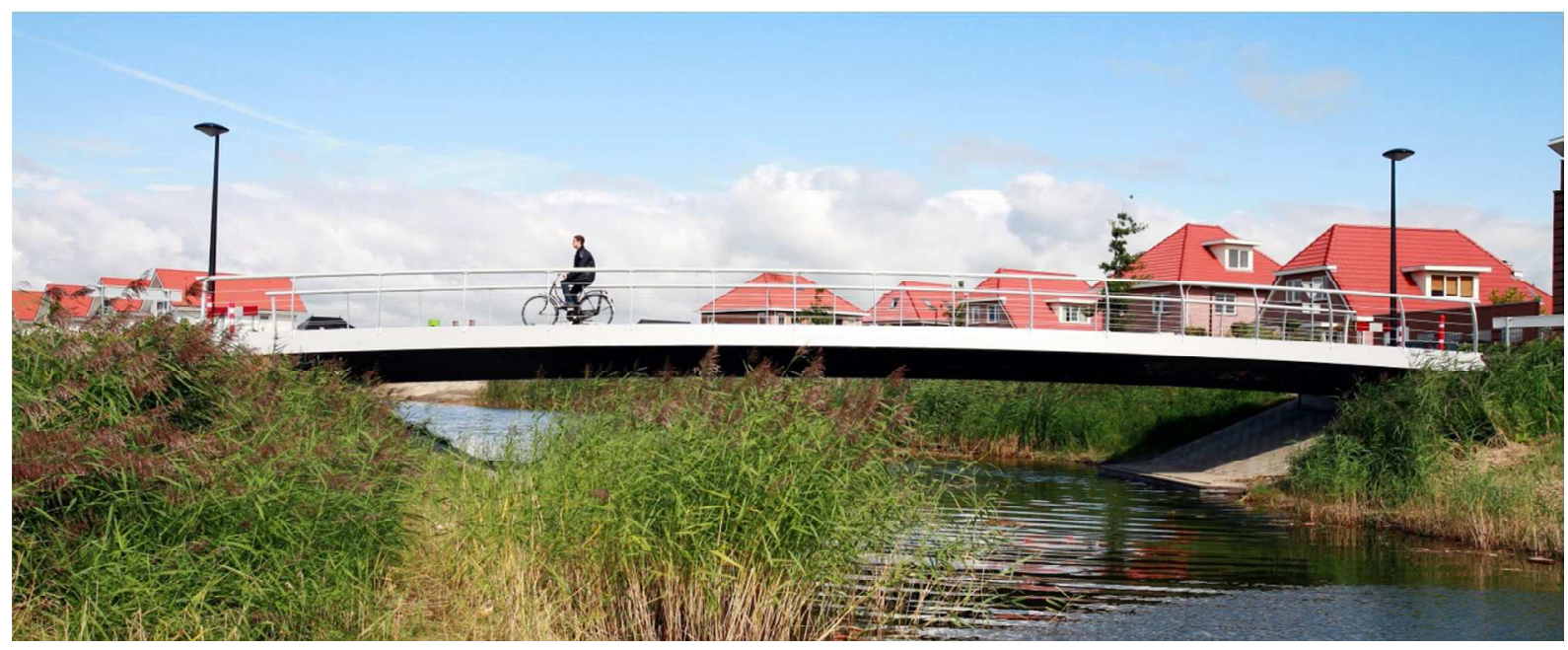

Figure 6: FiberCore technique for creating unitised structures [Peeters, 2011]

Although the architectural design of these bridges is minimal and limited to the design of the parapet, the bridges have a much lower span-to-depth ratio then all other examples shown above, and are therefore quit slender in appearance. 


\section{Challenges for the architect}

Now that we have seen how engineers coped with this new and exciting material the question of this paper still remains unanswered: what architectural means and challenges do architects have when it comes to designing bridges from FRP?

\subsection{Modular deck edge elements}

We started using FRP in bridge design in my office in 2005. We were looking for an elegant solution to make a slender edge on the side of the deck on the Juliana Bridge in Zaanstad. The edges we had in mind had to be very smooth and highly polished. They needed to have a $900 \mathrm{~mm}$ cantilever from the side of the concrete deck with a curved and tapered cross section. The parapets needed to be integrated in the modular shape in such a way that each module could still be demounted for inspection or cable replacement. Furthermore we were looking for a sophisticated seam in between the elements, instead of just cutting the plate material at a 90 degree angle, we wanted blind edges with an inner flange of $60 \mathrm{~mm}$ deep to camouflage montage tolerances and to prevent a visual dark gap in between the elements. As it turned out FRP was if the choice if not the only material to achieve such high level of fabrication.
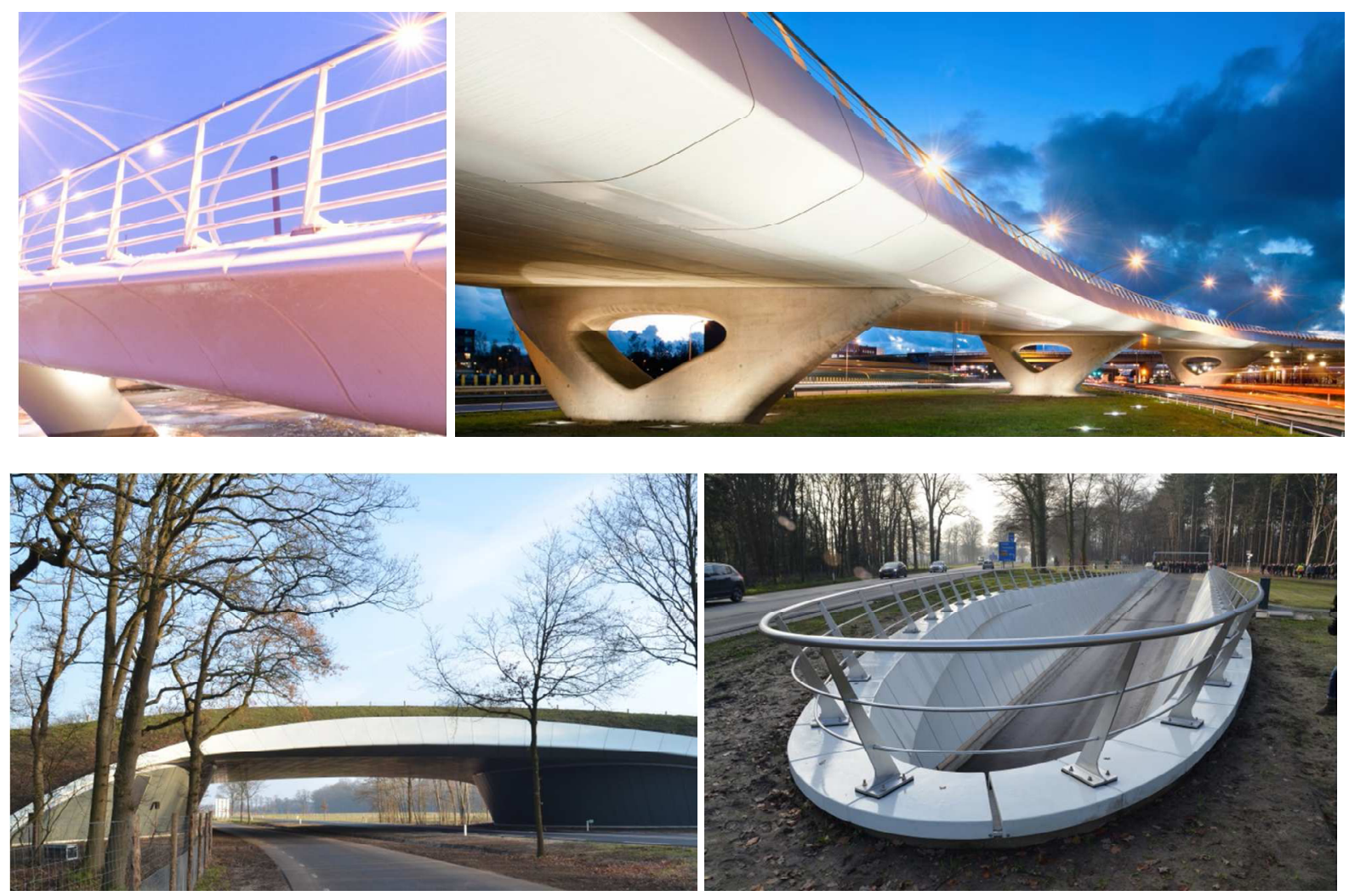

Figure 6: edge elements on the Juliana Bridge in Zaanstad (top left), the fly-over Waarderpolder in Haarlem (top right), and the wildlife crossing and tunnel in Rijssen-Wierden. [Royal HaskoningDHV, 2007, 2013, 2013]

After the Juliana Bridge, we started using FRP edge elements in 3 other projects, the fly-over Waarderpolder in Haarlem, the Nelson Mandela Bridge in Alkmaar and the wildlife crossing with pedestrian tunnel in Rijssen-Wierden.

In a generic way, edge elements very much define the appearance of our bridges. After all, the shape of a bridge is mostly seen and appreciated in elevation, seen from the field, from the water or from the side of a canal. Driving on a bridge shows us a nice view in the best of cases, but the 
bridge itself will mostly be limited to the asphalt, the guardrails and the parapets. Before we started using FRP our edge elements were either made out of solid concrete, nicely tapered to the end, or they were constructed as hollow steel noses. The later offering the advantage of offering an inspectable space for ducts and cables. In all cases durability proved to be a hard issue. Steel noses would start corroding from the inside, due to moisture condensation. Algae and moss would start growing on the faces of the concrete element.

Using FRP for the fabrication of edge elements not only eliminated those durability issues. It provided our bridges with a whole new facelift. In terms of finishing the FRP can be as smooth and shiny as a car's bodywork. The freedom of shapes and curvatures is much greater than the equivalent in steel. And the edges of each element can have smooth rounded flanges directed inwards. This bestows an industrial design appearance to the elements.

\subsection{Monocoque structures}

Now that we learned how to use FRP for smaller modular bridge elements, the next step was towards load bearing structures in FRP. Inspired by the monocoque decks produced by FiberCore, we started experimenting with the freedom of form that FRP has to offer. Monocoques are structures with a loadbearing exterior shell, comparable with shellfish. They offer the advantage that they can be very slender as the material is concentrated there were it is most efficient, on the outer regions of the cross section. From a maintenance and also aesthetical point of view the fact that the underside of the bridge is smooth and closed offers many advantages. Dirt doesn't accumulate on protruding flanges and birds can't build their nests in it. A first example of a monocoque bridge design in FRP is the Dragonfly Bridge in Harderwijk, the Netherlands.

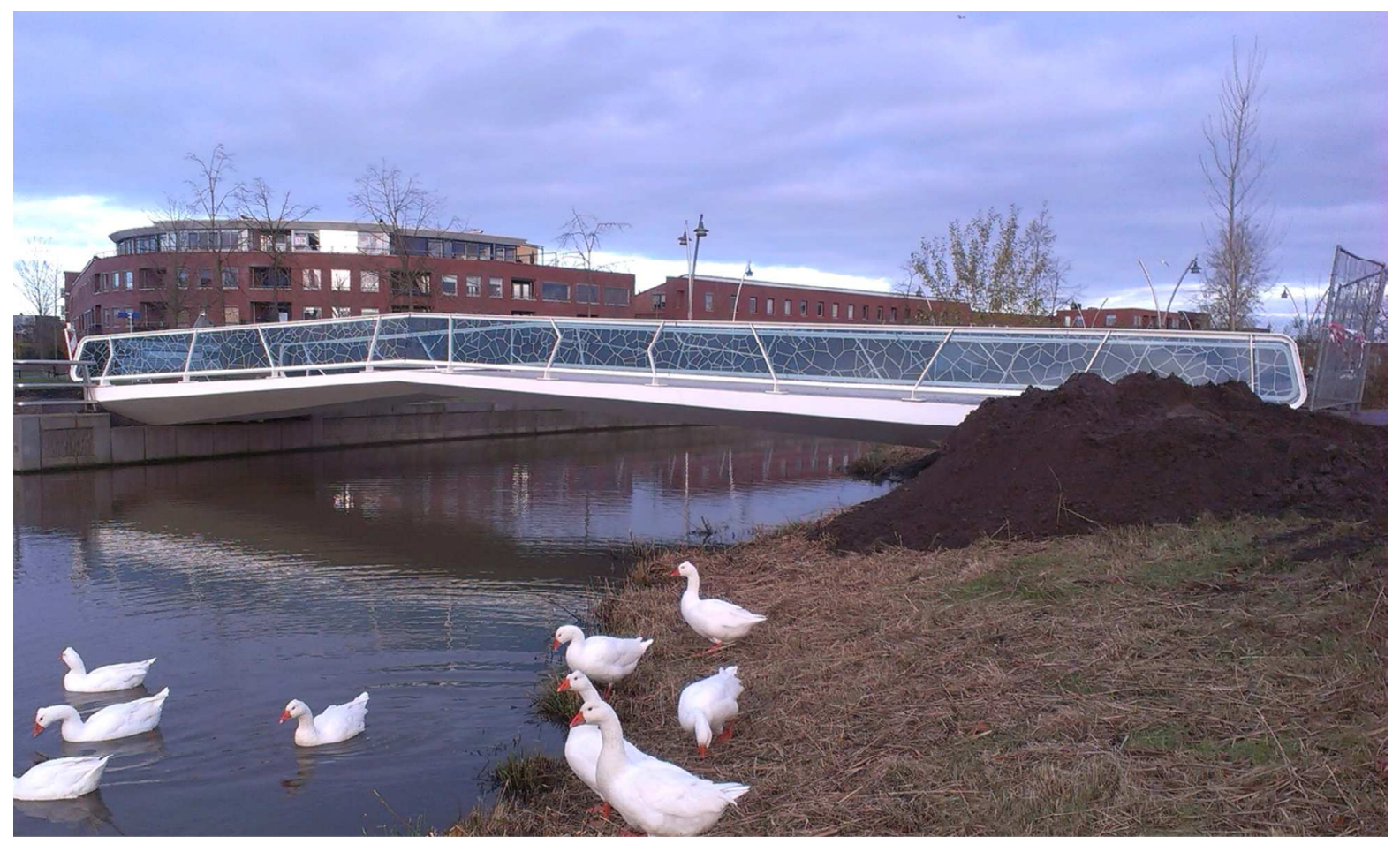

Figure 7: The Dragonfly footbridge in Harderwijk, the Netherlands. [Royal HaskoningDHV, 2014] 


\subsection{Shell structures and origami structures}

Another way of making a load bearing structure out of FRP is to make use of the intrinsic stiffness that three dimensional shell structures and folded structures have to offer. In these cases the deck itself can be quite thin as the structure derives its stiffness from 3D curvatures. An example of such a shell structure is our off-the shelf design for a modular FRP pedestrian bridge, developed in cooperation with aforementioned company FiberCore. The cross section of the deck curves upwards, forming part of the bridges' parapet. As the bending momentum increases towards the middle, so does the height of the shell.

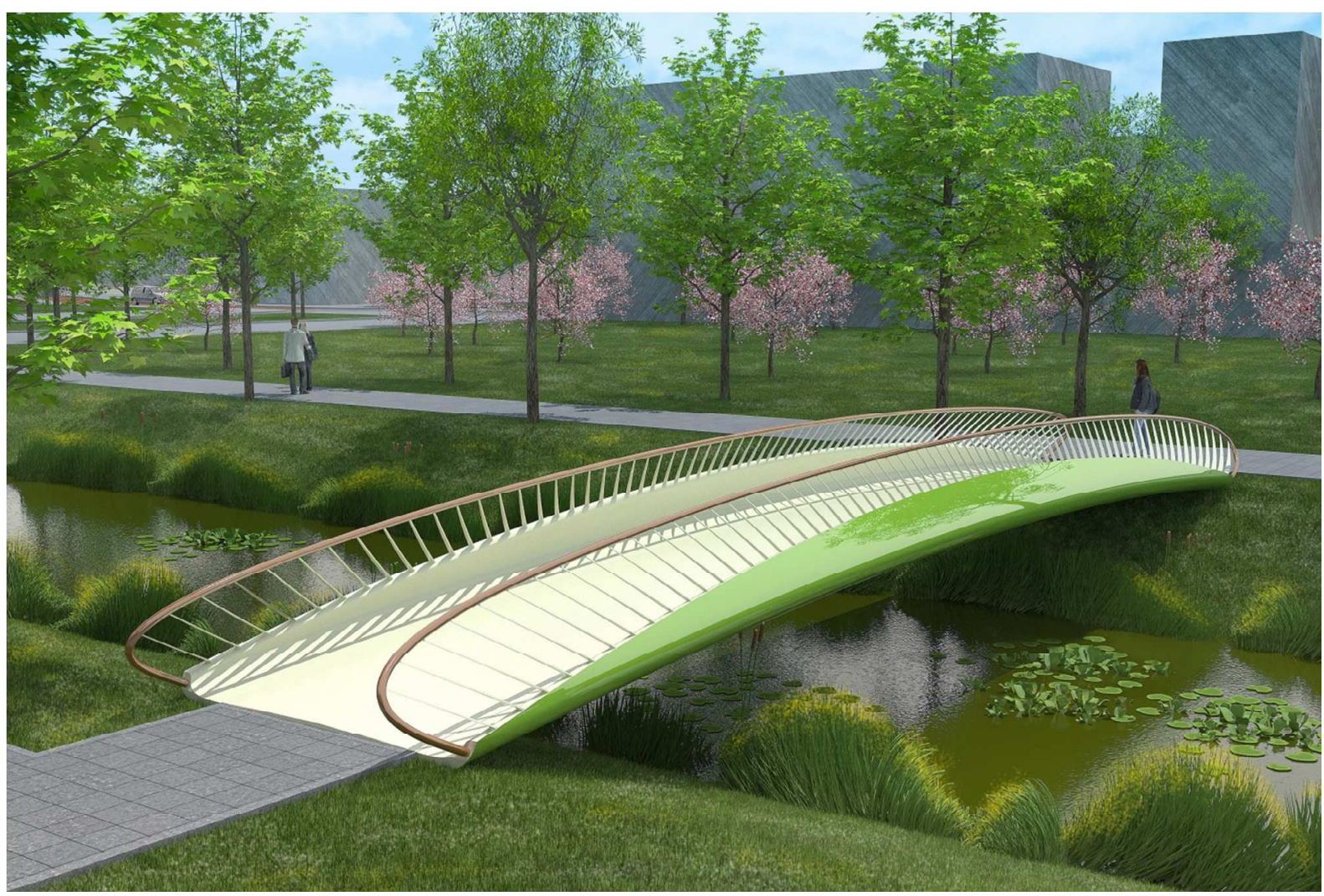

Figure 8: The Delft Design Composite Bridge for pedestrians and bicycles. [Royal HaskoningDHV, FiberCore, 2008]

\subsection{Bio composites}

Innovation doesn't stop with the use of FRP in bridge design. Sustainability in terms of CO2 footprint is becoming more and more important. Several studies have been done on the sustainability of FRP in comparison to traditional building materials such as steel and concrete. Even though 2 out of 3 studies point out that FRP performs better in terms of $\mathrm{CO} 2$ footprint, we still have to face the challenge improving. One way of doing so is to look at the raw materials that are used to build FRP. The majority of composite plastics used for structural elements consist of synthetic fibres such as glass fibre and carbon fibre combined with a petroleum-based resin.

In the late years, steps have been done on developing FRP based on renewable raw materials and creating products that found a variety of applications in the market. The automotive industry is a sector that has replaced most conventional polymers with natural fibre-reinforced polymers. In the building industry application include insulation products, cladding components for façade, flooring, connections or furniture. However, in the case of structural applications, the use of environmental 
friendly polymers on load-bearing elements is not yet tested. At TU Delft we are now conducting research that will eventually lead to the manufacturing of a bio composite bridge. Vegetable fibres from the flax plant, combined with a traditional petroleum based resin or combined with bio resin are used to design a 6 meter span footbridge in the Haarlemmermeer, the Netherlands. If all goes according to plan the design will be built as a first of its kind prototype.
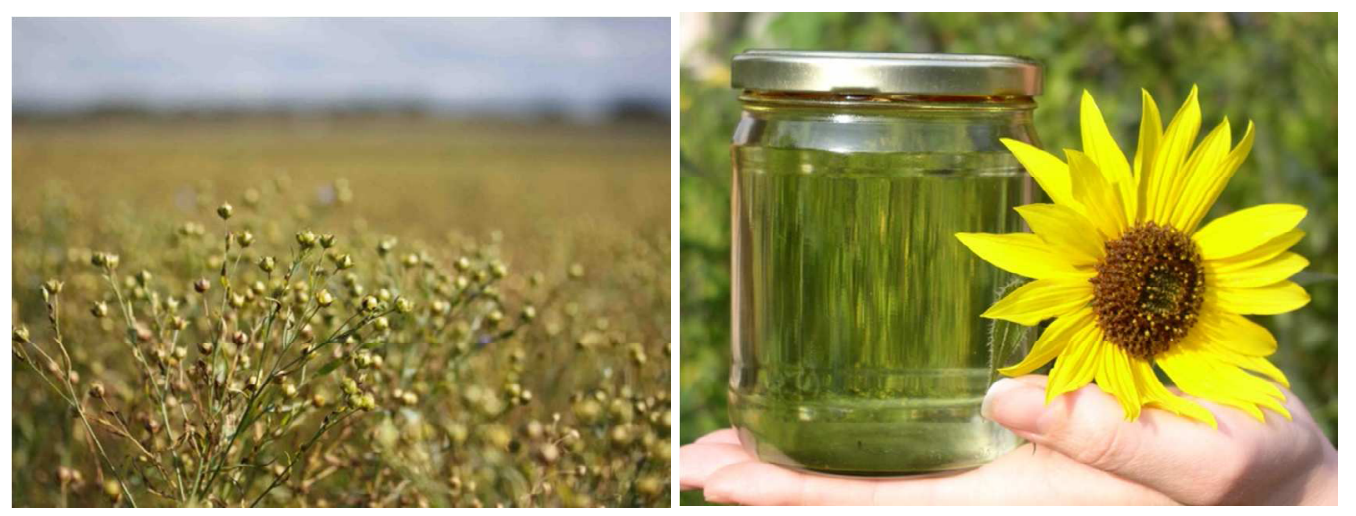

Figure 9: Fibres from flax and resins from the residual of bio-diesel. 